\title{
MORE SPACE AND IMPROVED LIVING CONDITIONS IN CITIES WITH AUTONOMOUS VEHICLES
}

\author{
J.M. VLEUGEL ${ }^{1} \&$ F. BAL ${ }^{2}$ \\ ${ }^{1}$ TU Delft, Civil Engineering \& Geosciences, The Netherlands. \\ ${ }^{2}$ RISSK, The Netherlands.
}

\begin{abstract}
Many people live in cities today. Many more will do so in future. This increases the demand for space and (space for) transport. Space to expand roads is usually scarce. Building tunnels or elevated bridges is very expensive. Solving one bottleneck creates another bottleneck downstream. More road infrastructure leads to more cars and more cars to more congestion and externalities. Megacities invest in large-scale (preferably underground) public transport while smaller cities lack the required number of travellers and the money to warrant the high investment costs. In a sustainable city, the supply of goods, services, water, energy and transportation should differ from the current practice. New technologies in car manufacture are interesting, in particular, the nearly roadworthy self-driving (autonomous) cars. It is still a demanding challenge to let these share roads with conventional cars, cyclists and pedestrians. Currently, cities lack the space for a separate network for these cars. A socially challenging alternative would be to replace all private cars by shared electric self-driving cars and small shuttle buses and integrate these with mass transport, cycling and walking. Passenger transport would need much less space for driving and parking. Congestion will vanish. Local air pollution, noise and use of resources to produce cars and road materials will be reduced. Reclaimed space can be used to create a more sustainable and social environment and to optimize city logistics. The building blocks of such a (public-private) system exist already or will become available in the future.
\end{abstract}

Keywords: car technology, externalities, mobility, space, sustainable planning.

\section{INTRODUCTION}

\subsection{The many challenges of sustainability}

Sustainability [1] is a very complex topic that attracts a high level of interest. It is relevant in discussions about global ecological issues like climate change and deforestation, and local issues like air pollution. Environmental economists explain environmental degradation caused by humans as a systems failure: a combination of market- and government failure [2].

Sustainability also has a socio-economic dimension. This is, in particular, apparent at international conferences, where rich and poor countries struggle to find common ground. Individuals should be educated to no longer separate their small contribution from the global environmental problems. They should also have the financial means to behave more sustainable. These are essential for an effective treatment of non-sustainable behaviour: a tragedy of the commons [3].

The core challenge is: how to find a synergy between ecological, social and economic concerns and interests? [4] What is the role of technical development in reaching this synergy? Is technology 'good' or 'bad'? Technology may indeed increase energy efficiency, reduce (air) pollution and other impacts. Yet, who or what determines which technologies are developed, introduced and used in practice? Are they technical 'fixes' with a short lifespan or structural solutions? Are they still effective at a higher level of demand (for the product or the activity) or will degradation of the environment and depletion of natural resources continue at a slower pace? 
Here, the focus is on developed countries where many have access to transparent sources of information and financial means. This makes it more an individual choice whether one accepts or rejects sustainability. Two extremes are seen in practice. There are those who downplay or even deny human contribution to climate change or environmental degradation. They may argue that there is still time to develop new and cheaper technologies, or hope that others take a higher share and/or pay for the transition. Their interests lie in short-term sustainability. They do not care about the public. On the other extreme, there are those who have changed the way they live, work, buy or use means of transport in order to save on energy, reduce emissions, control pollution etc. The majority is somewhere in between.

The debate about the necessity of sustainability, its direction and goals, form and planning is on going. There are signs that those who say no to sustainability are becoming a minority. Technical breakthroughs have lowered the costs of 'greener' technologies. Entrepreneurs make a positive business case of these enabling technologies. Consumers are interested if these substitute technologies add to their quality of life in a cost-effective way.

\subsection{Urbanization, sustainability and use of space}

In $2014,54 \%$ of the world population lived in urban areas, compared to $34 \%$ in 1960 . The WHO expects a global urban population growth of 1,84\% (2015-2020), 1,63\% (2020-2025) and $1,44 \%$ (2025-2030) [5]. Urban areas are attractive because they offer better jobs, houses, education, services and more extensive transport networks than rural areas. The demand for space in cities will grow as a consequence: a process also known as urban sprawl.

Citizens are in need of food and other (essential) goods and services, such as clean water, energy, a comfortable house, jobs and efficient transportation systems. In a sustainable city, it makes sense to produce food, other goods and energy locally or regionally if producing conditions allow, instead of importing these from all over the world. Mass-produced goods have a moderate price, because of low wages, poor working conditions and lack of effective environmental policies in most of these producing countries [6, 7].

\subsection{Sustainable cities and transport}

With so many people living in cities and many more to follow, it becomes even more important to effectively manage transport and its impacts.

Cities have local environmental policy targets and instruments. Car-free and environmental zones have become common. Local emission standards may also prevent the use of (certain) vehicles on a temporary or permanent basis. However, a sustainable, liveable city goes beyond that. It should have a clean, energy- and space-efficient traffic system.

A sustainable lifestyle means more cycling and walking and less car use. Mobile communications and the Internet can avoid commutation. Mixed traffic creates conflicts between road users and traffic accidents [8], which may seriously deter people from cycling or walking. Countries with dedicated infrastructure have more people who cycle and walk and therefore have less traffic accidents. With more citizens, more of such infrastructure is necessary.

\subsection{Environmental policies and vehicle technology}

The car industry has been in existence for well over a century. The environmental impact of mass motorization was largely neglected until the 1970s. Then it gradually changed in 
response to warnings from scientists, demands by car owners (fuel efficiency) and citizens (air quality, noise). Policy makers in developed countries have issued increasingly tighter energy-efficiency and emission standards and other regulations (treatment of waste, recycling).

Road transport amounted to around $81 \%$ of all energy used in transport (374 Mtoe) in EU-27. A decoupling of transport growth $(+30 \%)$ and $\mathrm{CO}_{2}$ emissions $(+10 \%)$ took place between 1999 and 2008 [9].

Environmental policies stimulate introduction of more energy- and resource-efficient and cleaner technologies. Is it possible to reach national or local targets regarding energy reduction and emissions to the environment by technical progress alone? A major study of future energy scenarios for The Netherlands for 2050 sheds some light on this. Technical progress in car and fuel technologies and the future demand for transport are quite uncertain. It also takes decades to phase out current car technologies. In the reference scenario, transport would generate 43 Megaton of $\mathrm{CO}_{2}$ (on a well-to-wheel (WTW) basis) in 2050. The national policy target for 2050 is $-60 \%$ of this amount. It could come from electric cars and LNG-powered trucks in cities and a partially green electricity production. This is quite an optimistic scenario, which strongly deviates from the current situation. Substantial use of hydrogen cars is needed to go beyond this $-60 \%$. If technical progress does not speed up, then fewer kilometres per person is necessary (volume reduction). About 10\%-20\% of the WTW emissions of $\mathrm{CO}_{2}$ are from the well-to-tank (WTT) process. A greening of that process is uncertain, but relevant, because it could compensate for slow progress in automotive technology or volume reduction. Alternatively, faster technical progress may put less stress on the speed for improvement of the WTT process. Emission reduction of $\mathrm{CO}_{2}, \mathrm{NO}_{\mathrm{x}}$ and PM10 is necessary because of climate and health concerns. If local emission standards (which are not met along many city roads today) are to be increased substantially, then an even bigger effort would be necessary [10].

\subsection{New automotive technologies}

In this article two technologies are in focus. The first is engine and fuel technology (Section 2.3). The second is self-driving vehicles (Section 2.4).

\subsection{Goal and main questions}

\subsubsection{Goal}

The article sketches a future where a city could have a more sustainable and space-efficient integrated transport system. The research started with [11].

\subsubsection{Main questions}

The following questions will be addressed:

1. Which types of land-use in cities need more space in future? This question has already been addressed qualitatively in Sections 1.2 and 1.3.

2. Which uses of space are enhancing each other and which do not or may even exclude each other?

3. What are the design criteria and constraints for an alternative transport system for a city?

4. What amount of space could potentially be released to non-transport activities if a new integrated transport system would be in use? 
5. What would be the potential reduction in emissions of $\mathrm{CO}_{2}, \mathrm{NO}_{\mathrm{x}}$ and $\mathrm{C}_{\mathrm{x}} \mathrm{H}_{\mathrm{y}}$ ?

6. How realistic is the proposed transport system? Is public policy needed to introduce and support this new transport system?

\subsection{Scope and time horizon}

Developed countries challenged by urbanization can also provide the facilities for new ways of transporting people and goods. New car technology is tested on their roads. A virtual city with 1 million people is used to assess the potential to reduce space and emissions of cars if shared self-driving electric shuttles replace conventional cars. The time horizon of the article is 2040. This year aligns with the current road tests of autonomous vehicles (AV) and the growing use of electric cars and a reasonable pace of technical progress. It allows for a gradual adaptation of the road infrastructure and services like fuel stations. The virtual city is sustainable by 2040 .

The country of reference is The Netherlands, because of the growing use of electric cars and electric public transport. The city of reference is Amsterdam with 834.713 citizens (2016), which may grow past 900.000 in 2040 [12].

This article is also relevant for citizens in developing countries. They may learn from experiments and (costly) mistakes in developed countries. There are more ways to develop socio-technical systems. An example is the telephone system. African nations skipped the rollout of cable networks and went straight for wireless networks, because of technical, practical and financial reasons.

\subsection{Set-up}

The paper continues with Section 2 - Sustainable cities and their challenges. Section 3 deals with methodology and scenario assumptions. Section 4 presents the estimated reduction in the use of space and emissions after introduction of the new transport system. Section 5 follows with an evaluation and final conclusions.

\section{SUSTAINABLE CITIES AND THEIR CHALLENGES}

\subsection{Introduction}

Land-use in and around cities is continuously changing due to public and private policies and initiatives [13]. In cities with effective spatial planning, developers have many options to (re-) use space. Some of these are compatible and may be in the same plan. For instance, new houses can be combined with (clean, low noise) jobs in mixed developments. Empty offices may be turned into apartments for students and starters. Empty factories can be re-used or renovated or demolished to provide space for different activities. In a sustainable city, more green spaces and water are also needed. The number of citizens will drastically rise in future. Combining both, a city either expands or some activities reduce their spatial footprint. Roads are omnipresent. Traffic plying on these roads has positive (socio-economic) as well as negative effects (externalities): air pollution, noise, accidents, di-section of areas, consumption of energy and other resources, use of space for driving and parking and serious health concerns. The challenge is how to move more people and significantly reduce these externalities and impacts.

This answers research question 2 in a qualitative way. 
2.2 Towards a smart and sustainable transport system

\subsubsection{Introduction}

A new transport system may be designed with systems engineering [14]. Its capabilities should match the following key requirements: sustainability, space-efficiency, availability and affordability and no technical or other implementation barriers.

The suggestions on requirements, criteria and constraints provided are those of the authors.

\subsubsection{Design criteria}

The new transport system should then fulfil the following criteria:

1. Reduce energy consumption and zero air pollution;

2. Reduce noise emission;

3. Reduce amount of space used directly and indirectly;

4. Reduce quantity of raw materials used in production, construction and maintenance of vehicles and infrastructure;

5. Reduce need for mobility and number of kilometres driven per unit of time ('smart mobility' [15]);

6. Optimize accessibility and transfer between subsystems ('seamless');

7. Fulfil demand by scalable, flexible supply ('on demand');

8. Use proven technology and accepted concepts like shared cars [16];

9. Allow (future) integration of city logistics vehicles.

\subsubsection{Design constraints}

The following constraints are used to optimize the system:

1. All vehicles are owned by a public/private entity, they are in shared use;

2. Vehicles and services are complementary, not competitive;

3. User fees differ per target group, vehicle occupancy rate and time of the day;

4. The new system does not violate (local) laws and regulation.

This answers research question 3.

\subsubsection{Final design goal}

The new transport system should ultimately allow more people to live in a city in a sustainable way and help to slow down urban sprawl.

\subsection{Car technology 1: engines and fuels}

In the past decade (hybrid)-electric car technology has reached maturity. In 2016, $1 \%$ of all cars on the road were electric worldwide. These numbers differ per country and city. National governments may subsidize purchase of electric cars, like in The Netherlands, Norway and the United States [17]. Regional or local governments may also have specific policies (e.g. for local charging). More electric cars are sold, but the large majority of new cars still have a conventional engine. The industry is also testing hydrogen fuel with a driving range similar to that of petrol and diesel, which is still a decisive buying argument for electric cars, which are more expensive and have to be recharged regularly. Car manufacturers share development 
of technology and production of parts, which speeds up technical development and reduces the cost per vehicle [18].

\subsection{Car technology 2: self-driving}

A self-driving car has additional technical systems [19], which allow it to drive itself through traffic. There are five stages of self-driving $(0=$ no automation and $5=$ driver-less car). Current cars use stage 2 (speed control, lane assistance based on data from cameras and radar/ lidar). The driver supervises the car and must be ready to take control of the driving wheel at all times.

\subsection{The new transport system}

In 2040, all cars will be replaced by so-called e-shuttles of 2 sizes: cars (4-5 passengers) and minibuses (8-18 passengers). These are level 5 cars with centralized supervision as fall-back. A mix of on-demand and scheduled supply is foreseen. In order to have a balanced use of e-shuttles and mass transit and to optimize the amount of vehicles simultaneously underway, trip payment is based on the vehicle occupancy rate and the value of time of the passengers. Road infrastructure will be redesigned to meet the demands of the new system.

\section{METHODOLOGY AND SCENARIO ASSUMPTIONS}

\subsection{A model}

In an ideal world, the interests of all stakeholders would be perfectly in tune. Large, open databases would allow researchers to build and use very complex multi-dimensional and multi-layered models of a city, supported by real-time data about behaviour of all individuals in the city. In the real world technical, financial, privacy and practical constraints ask for a more aggregated approach. An MS $\odot$ Excel $\odot$ model was developed to estimate current and future use of space savings and emissions after the introduction of the integrated transport system.

\subsection{Spatial footprint (current)}

Cars use road space and parking space. For parking, a car requires around $10 \mathrm{~m}^{2}(4 \times 2$ plus turn in/out). At least 212 hectares $\left(1\right.$ ha $\left.=10^{4} \mathrm{~m}^{2}\right)$ is needed for parking.

Amsterdam has a historic city centre, an extensive canal network and road network. It has much more water than the average city. During 2011, its space was used as follows [20]: Traffic (7,3\%; roads $5,5 \%$ (or 1202,57 hectares)), houses $(20,6 \%)$, business $(10,5 \%)$, water $(24,8 \%)$, agriculture $(12 \%)$, forest or nature $(2,1 \%)$, recreation $(11 \%)$, development $(6 \%)$ and services $(4,8 \%)$.

Table 1: Car data in the base scenario.

\begin{tabular}{lll}
\hline & Numbers & Car occupancy (average persons) \\
\hline Car travellers & 350.000 & 1,65 \\
Cars & 212.120 & \\
Parking space & $212.1210 \mathrm{~m}^{2}$ & \\
\hline
\end{tabular}




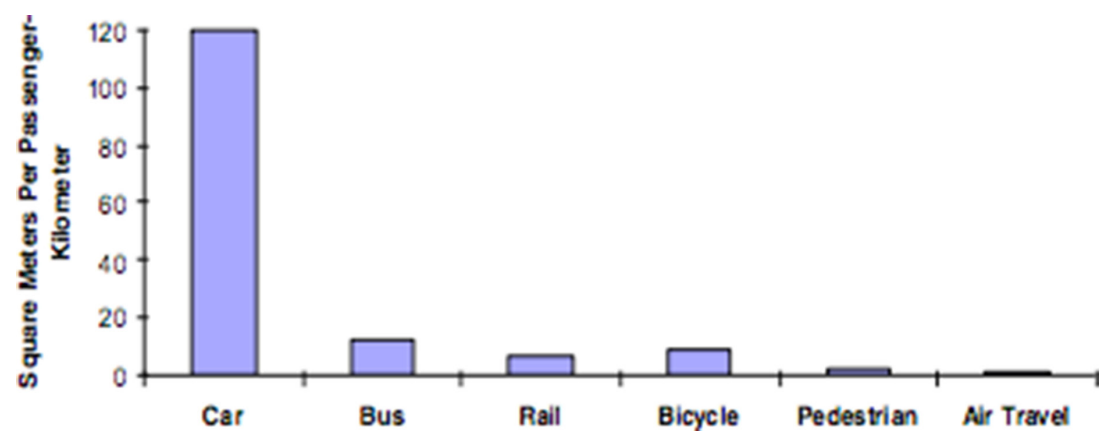

Figure 1: Use of space by mode of transport [22].

It is assumed that roads take at least $10 \%$ of the space in the virtual city, due to road geometry, space for noise barriers and separation, and parking.

Car driving is by far the most inefficient way of using space (Fig. 1).

\subsection{Mobility scenarios}

To estimate daily mobility, daily average values for The Netherlands [21] were used, except for public transport, where much higher values were used, because the national average includes many areas without regular public transport (Table 2).

Table 2: Mobility scenarios for 2017 and 2040.

\begin{tabular}{lcccc}
\hline Mode of transport & $\begin{array}{l}\text { Travellers } \\
\text { per day }\end{array}$ & $\begin{array}{l}\text { Kilometres } \\
\text { per day }\end{array}$ & $\begin{array}{c}\text { Travellers } \\
\text { per day }\end{array}$ & $\begin{array}{l}\text { Kilometres } \\
\text { per day }\end{array}$ \\
\hline Walking & 100.000 & 1 & 130.000 & 1 \\
Biking & 295.000 & 3 & 383.500 & 3 \\
Moped/scooter & 5.000 & 15 & 5.500 & 15 \\
e-Moped/scooter & & & 130.000 & 15 \\
Bus electric & 0 & 0 & 0 & 0 \\
Bus Diesel & 80.000 & 15 & 0 & 0 \\
Bus CNG & 20.000 & 15 & 65.000 & 15 \\
Metro & 50.000 & 15 & 130.000 & 15 \\
Tram & 100.000 & 15 & 0 & 0 \\
Car petrol & 280.000 & 15,3 & 0 & 0 \\
Car Diesel & 66.500 & 15,3 & 0 & 0 \\
Car PHEV petrol & 28.000 & 15,3 & 0 & 0 \\
Car FEV & 7.000 & 15,3 & 0 & 0 \\
Taxi & 1.000 & 15 & 1.200 & 30 \\
e-Van (trips) & 0 & 0 & 0 & 0 \\
Van (trips) & 1.000 & 30 & 1.200 & 30 \\
e-Truck(trips) & & 30 & 0 & 50 \\
Truck (trips) & 1.000 & 0 & 455.000 & \\
e-Shuttle & 0 & & & \\
\hline
\end{tabular}


The following assumptions were also used:

- The number of people living in the city will rise by 30\% compared to 2017 .

- Daily mobility per mode of transport stays the same.

- Sustainable mobility will lead to more cycling and walking. There will be more elderly people, who have a (much) lower daily mobility.

\subsection{Ecological footprint}

Emissions of $\mathrm{CO}_{2}, \mathrm{NO}_{\mathrm{x}}$ and $\mathrm{PM}_{10}$ were estimated as follows:

1. Mode of transport, average number of travellers per day, propulsion category, energy category, energy mix, estimated distance in kilometres per mode, split by engine/fuel type per day etc. and occupancy rate.

2. Multiply combination 1) kilometres with the emission parameters per fuel.

3. Multiply 2) by number of days per year.

4. Sum 3).

\section{IMPACT OF THE NEW TRANSPORT SYSTEM}

\subsection{Introduction}

This section presents the use of space and emissions by the new transport system based on the data and assumptions of Section 3.

4.2 Re-use of space in 2040

\subsubsection{Parking space}

It follows from Section 3.2 that 212 ha of space were used for parking. In future, permanent parking will disappear near buildings, because shared vehicles will be parked and recharged in special garages off-street. Not all of the 212 ha can be re-used, because of two reasons. First, if parallel lanes are removed, then some bypasses are needed to prevent gridlock. Second, dedicated parking lots should be available per street to improve the rather challenging city logistics [23]. Hence, a reduction of parking space to $80 \%(42,4 \mathrm{ha})$ is assumed.

\subsubsection{Roads}

It is argued [24] that all people in this country could be transported with $20 \%$ of the cars on the road today. This assumes that cars would have an occupancy rate of 4-5, where 1,65 persons is the current average. If we assume a more modest occupancy rate of e-shuttles and some expansion of the public transport network to deal with peak demand, then the new integrated transport system might still take much less space, probably $-50 \%$ or around 1100 hectares in the case of a city like Amsterdam. Applied to that city, this means that the area available for development (now 6\%) would be roughly twice the size.

Re-use of space on a large scale is in the blood of cities. It has happened with railways and tramlines, but for roads it has not been practiced, yet.

Research question 4 is now answered. 


\subsection{Emissions in 2017 and 2040}

The new integrated transport system based on large-scale electrification and shared use has a major impact on the emissions in the virtual city (Table 3).

\subsection{Validation of the results}

The estimated use of space can be put in perspective. In 2015 [25], Amsterdam had 228.691 cars and 156473 parking locations, partially offered in parking garages. There are more cars than parking locations at street levels, because of the policy to restrict car use. The 212.120 cars in the model city are rather realistic.

$\mathrm{CO}_{2}$ emissions for the same year were estimated as $843 \mathrm{kton}$ : 690 (cars), 127 (mid-heavy trucks), 26 (very low-emission buses). Our 727 Kton was based on the mobility scenarios.

Table 3: Estimated local emissions by mode of transport.

\begin{tabular}{llll}
\hline 2017 - Mode of transport & $\mathbf{C O}_{\mathbf{2}}$ & $\mathbf{N O}_{\mathbf{x}}$ & $\mathbf{P M}_{\mathbf{1 0}}$ \\
\hline Walking & 0 & 0 & 0 \\
Biking & 0 & 0 & 0 \\
Moped/scooter & 6.885 .281 & 3793 & 4.612 \\
Bus Diesel & 93.943 .511 & 389.954 & 91.462 \\
Bus CNG & 44.739 .618 & 61.100 & 842 \\
Metro & 0 & 0 & 0 \\
Tram & 0 & 0 & 0 \\
Car petrol & 392.586 .175 & 216.277 & 262.993 \\
Car petrol parking ${ }^{1)}$ & 25.659 .227 & 14.136 & 17.189 \\
Car Diesel & 91.394 .450 & 379.373 & 88.980 \\
Car Diesel parking ${ }^{1)}$ & 5.973 .493 & 24.796 & 5.816 \\
Car PHEV petrol & 8.836 .724 & 4868 & 5.920 \\
Car PHEV petrol parking & 577.564 & 318 & 387 \\
Car FEV & 0 & 0 & 0 \\
Taxi & 23.178 .225 & 96.212 & 22.566 \\
Taxi parking ${ }^{1)}$ & 1.545 .215 & 6414 & 1504 \\
e-Van & 0 & 0 & 0 \\
Van & 5.770 .905 & 23.955 & 5.618 \\
Van parking ${ }^{1)}$ & 192.365 & 798 & 187 \\
Truck & 25.543 .350 & 106.029 & 24.869 \\
Truck parking ${ }^{1)}$ & 851445 & 3534 & 829 \\
Total (gram) & 727.677 .547 & 1.331 .558 & 533.774 \\
Total (Kton) & $\mathbf{7 2 7}$ & $\mathbf{1 , 3}$ & $\mathbf{0 , 5}$ \\
2040 - Mode of transport & & & \\
All & $\mathbf{0}$ & $\mathbf{0}$ & $\mathbf{0}$ \\
\hline Not & & & \\
\hline
\end{tabular}

Note: It is assumed that the average search for a parking place takes 5 minutes and 1 kilometre. This (under-)estimation already adds considerably to emissions. 
Use of the actual data for Amsterdam would have closed the gap between the two datasets. The model is therefore regarded as valid.

\subsection{Conclusions}

The integrated transport systems leads to a major reduction in the use of space $(50 \%)$ and emissions by transport: 727 Kton of $\mathrm{CO}_{2}, 1,3$ Kton of $\mathrm{NO}_{\mathrm{x}}$ and $0,5 \mathrm{Kton}$ of $\mathrm{PM}_{10}$. This answers research question 5 .

\section{EVALUATION AND FINAL CONCLUSIONS}

To propose a new system for the currently largely unsustainable passenger transport seems daring, but not so much if one takes into account technical progress. Self-driving cars will enter the mass market. The technology is partially already inside conventional cars. A new system is needed because mass motorization has reached its limits. Within a few years from now many (major) cities will face gridlock. Building more roads inside a city is usually impossible. Building roads around a city enhances urban sprawl and destroys the environment. Roads are full again after a few years. Accessibility is essential for the socio-economic prosperity of cities. Cars use far too much energy and as a consequence emit large amounts of $\mathrm{CO}_{2}, \mathrm{NO}_{\mathrm{x}}$ and $\mathrm{PM}_{10}$, to name just of few of the many externalities. Many people and businesses have reduced energy consumption and ecological footprint by shifting to different products or lifestyles. Transport is still an exception; it continues to grow, as do its total energy consumption and emissions. Electrification of individual cars is not enough; it is the volume that matters most. Another reason is that it uses far too much space compared to an alternative system. This alternative helps to reduce the use of space and emissions, which is necessary to make cities sustainable and liveable again.

Change will also come because mobility needs and preferences regarding ownership and use of cars are changing. Electronic communication may replace mobility partially as well. Policy instruments like environmental zones and car-free streets, parking policy, charging infrastructure etc. should be accompanied by road redesign to support the introduction of shared self-driving cars.

\section{ACKNOWLEDGEMENT}

This paper is part of our joint research initiative STEER (Strategic Transport Environment and Energy Research). We thank the anonymous reviewer.

\section{REFERENCES}

[1] "Development which meets the needs of current generations without compromising the ability of future generations to meet their own needs". World Commission on Environment and Development (WCED). Our Common Future (Brundtland Report), Oxford University Press, Oxford, 1987.

[2] Keech, W.R., Munger, M.C. \& Simon, C., Market failure and government failure, Public Choice World Congress 2012 Miami. Market failure refers here to low price of environmental goods or -impacts. Government failure refers to inefficient, ineffective or counterproductive government policies or instruments. Joint study of both helps to understand systems failure, 2012, available at http://michaelmunger.com/papers/keechmungersimon.pdf

[3] Hardin, G., The tragedy of the commons. Science, 162, pp. 1243-1248, 1968. https://doi.org/10.1126/science.162.3859.1243 
[4] Robinson, J., Squaring the circle? Some thoughts on the idea of sustainable development. Ecological Economics, 48, pp. 369-384, 2004.

https://doi.org/10.1016/j.ecolecon.2003.10.017

[5] WHO, available at www.who.int/gho/urbanhealth/situation_trends/urban_population growth_text/en/.

[6] Corbett, M.F., The outsourcing revolution, why it makes sense to do it right, available at http://www.economist.com/media/globalexecutive/outsourcing_revolution_e 02.pdf, 2004.

[7] Mitchell, A., Environmental impacts of outsourcing, available at www. ecommerce times.com/story/37421.html, 2004.

[8] NHTSA, Bicyclists, available at www.nhtsa.gov/road-safety/bicyclists.

[9] Eurostat, Energy, transport and environmental indicators, ISBN 978-92-79-16303-6, Luxembourg, 2016.

[10] CE, ECN, TNO, Scenarios for energy carriers in the transport sector. Delft/The Hague, 2014.

[11] Vleugel, J. \& Bal, F., Hoe SMART willen we rijden; De autonome auto als stedelijke vervoersoplossing of -probleem? Colloquium Vervoers planologisch Speurwerk (CVS), Zwolle, November, 24-25 2016.

[12] Gemeente Amsterdam, available at www.ois.amsterdam.nl/visualisatie/bevolking.html

[13] E.g., USGS, Analyzing Land Use Change In Urban Environments, available at https:// landcover.usgs.gov/urban/info/factsht.pdf

[14] Dym, C.L. \& Little, P., Engineering design, A project-based introduction, 2nd edn., John Wiley \& Sons, New York, 2004.

[15] Smart mobility explores how the city changes with the development of transportation and telecommunication technologies, available at www.mobile.mit.edu/ projects/smartmobility, MIT Mobility Experience Lab.

[16] Steiner, J., Wappelhorst, S. \& Graff, A., Free-floating e-car sharing: Integration in public transport without range problems. European Transport Conference, Frankfurt, 29-09-01-10 2014, 2014-08-26_ETC_2014_E-CS substitution.pdf

[17] Growth in electric vehicles sales central to closing emissions, available at www. worldenergy.org/news-and-media/news/growth-in-electric-vehicles-sales-central-toclosing-emissions-gap/

[18] Muffatto, M., Platform strategies in international new product development. International Journal of Operations \& Production Management, 19(5/6), pp. 449-460, 1999. https://doi.org/10.1108/01443579910260766

[19] Zhao, L., Ichise, R., Mita, S. \& En Sasaki, Y., Core ontologies of driverless cars, Toyota Technological Institute, Nagoya and National Institute of Informatics, Tokyo, Japan, 2015.

[20] Gemeente Amsterdam, Statistisch Jaarboek 2013, available at www.ois.amsterdam.nl / pdf/2013_jaarboek_hoofdstuk_08.pdf.

[21] Litman, T., Evaluating public transit benefits and costs, Best practices guidebook, Victoria Transport Policy Institute, Canada, 2016.

[22] CBS, Onderzoek Verplaatsingen in Nederland (OVIN) 2015, Onderzoeksbeschrijving, Heerlen, 2015.

[23] Vleugel, J.M., Modelling goods city distribution in the Netherlands. European Transport, Issue 28, pp. 20-33, 2004.

[24] Heirbaut, J., Ons economisch system werkt niet meer, interview with prof.dr.ir. D. Helbing. De Ingenieur, 12, pp. 44-47, 2016.

[25] Cition, Amsterdam in cijfers, 2016. 